\title{
Loss of neurovirulence is associated with reduction of cerebral capillary sequestration during acute Babesia bovis infection
}

\author{
Kerry S Sondgeroth ${ }^{1 *}$, Terry F McElwain ${ }^{1,2}$, Andrew J Allen ${ }^{3}$, Annie V Chen ${ }^{3}$ and Audrey OT Lau ${ }^{1,2}$
}

\begin{abstract}
Background: Severe neurological signs that develop during acute infection by virulent strains of Babesia bovis are associated with sequestration of infected erythrocytes in cerebral capillaries. Serial passage of virulent strains in cattle results in attenuated derivatives that do not cause neurologic disease. We evaluated whether serial passage also results in a loss of cerebral capillary sequestration by examining brain biopsies during acute disease and at necropsy.
\end{abstract}

Findings: Cerebral biopsies of spleen intact calves inoculated intravenously with a virulent or attenuated strain pair of $B$. bovis were evaluated for capillary sequestration at the onset of babesiosis and during severe disease. In calves infected with the virulent strain, there was a significant increase in sequestration between the first and second biopsy timepoint. The attenuated strain was still capable of sequestration, but at a reduced level, and did not change significantly between the first and second biopsy. Necropsy examination confirmed the second biopsy results and demonstrated that sequestration identified at necropsy reflects pathologic changes occurring in live animals.

Conclusions: Loss of neurovirulence after serial in vivo passage of the highly virulent T2Bo strain of B. bovis in splenectomized animals is associated with a significant reduction of cerebral capillary sequestration. Previous genomic analysis of this and two other strain pairs suggests that this observation could be related to genomic complexity, particularly of the ves gene family, rather than consistent gene specific differences. Additional experiments will examine whether differential gene expression of ves genes is also associated with reduced cerebral sequestration and neurovirulence in attenuated strains.

Keywords: Babesia bovis, Babesiosis, Cytoadherence, Sequestration, Attenuation, Neurovirulence

\section{Findings}

\section{Background}

Babesia bovis is a tick-borne apicomplexan parasite that infects cattle in tropical and sub-tropical regions worldwide. Neurological signs may accompany fever and anemia during acute infection by many virulent strains [1]. Neurovirulence is associated with infected erythrocytes cytoadhering to endothelial cells, which subsequently leads to sequestration within cerebral capillaries [2-4]. Attenuated strains of B. bovis incapable of inducing neurovirulence are derived in vivo through rapid

\footnotetext{
*Correspondence: kss@vetmed.wsu.edu

1 Department of Veterinary Microbiology and Pathology, College of Veterinary Medicine, Washington State University, Pullman, WA 99164-7040, USA Full list of author information is available at the end of the article
}

serial passage of parental virulent strains, and are currently used as live vaccines in endemic regions [5]. Loss of neurovirulence associated-attenuation is hypothesized to be due to loss of endothelial cell cytoadherence and sequestration. However, the absence of sequestration has not been proven experimentally, particularly in live animals during acute infection. The mechanism of cytoadherence is postulated to involve endothelial cell binding of infected erythrocytes through interaction of the large protein gene family, Variant Erythrocyte Surface Antigen (VESA)-1, with the endothelial cell surface, similar to the mechanism of sequestration and neurovirulence in falciparum malaria involving the PfEMP1 protein family $[6,7]$.

In this study, we tested whether the loss of neurovirulence in animals infected with the attenuated strain

\section{Biomed Central}


is due to the absence of cerebral capillary sequestration. Temporal evaluation of capillary sequestration was performed in vivo by cerebral biopsies during acute infection, and in tissues taken at necropsy.

\section{Methods}

\section{Strains}

The T2Bo virulent strain of B. bovis and an attenuated derivative strain obtained after 29 passages in splenectomized calves was utilized. The virulent parental (T2Bo_vir) and attenuated derivative strains (T2Bo_att) have been previously validated to reflect their designated phenotypes of neurovirulence and non-neurovirulence, respectively [8].

\section{Animals}

The study utilized spleen intact Holstein cattle $>12$ months of age. Calves were initially obtained at 3-6 months of age from a Washington State dairy, quarantined at the Washington State University Animal Resource Unit, and given health checks at the Veterinary Teaching Hospital (College of Veterinary Medicine, Washington State University). All cattle were free of previous B. bovis infection as determined by sourcing from the United States (which is declared free of bovine babesiosis by the World Organization for Animal Health) and by confirmation through the absence of serum antibody and parasites by cELISA (VMRD, Pullman, WA) and qPCR, respectively, as previously described [9]. All animal procedures were approved by the Animal Care and Use Committee, \#ASAF 03322-002.

\section{Brain biopsy}

Two groups of spleen intact cattle ( $\mathrm{n}=2$ for each group) were intravenously inoculated with blood stabilates containing $2 \times 10^{7}$ infected erythrocytes (iRBC) of T2Bo_vir or T2Bo_att strain. Rectal temperature, hematocrit, and parasitemia were monitored daily. One day after the onset of fever $\left(>103^{\circ} \mathrm{F}\right)$, animals were anesthetized, placed in sternal recumbency, and a brain biopsy performed at the Veterinary Teaching Hospital (Washington State University, Pullman WA). Cerebral cortical tissue was obtained using a 14 gauge sidecutting disposable brain biopsy needle (Ad-Tech, Racine WI). Multiple $2 \mathrm{~mm} \times 1 \mathrm{~cm}$ pieces of biopsy tissue were fixed in $10 \%$ buffered neutral formalin for subsequent microscopic evaluation. Following the first biopsy, each animal was recovered from anesthesia and clinical signs monitored. The biopsy process was repeated within 2-3 days when clinical parameters indicated severe clinical disease. All animals were euthanized after the second biopsy while under anesthesia to evaluate capillary sequestration levels after the cessation of blood flow.
Post-mortem brain and tissue samples were collected in duplicate. One sample was placed in $10 \%$ buffered neutral formalin for fixation, and the second sample was frozen in liquid nitrogen for DNA extraction and qPCR analysis.

\section{Microscopic evaluation}

Formalin fixed tissues were paraffin embedded, cut into 5 micron sections, placed on glass slides and stained with Giemsa (Washington Animal Disease Diagnostic Laboratory). Sequestration of B. bovis iRBC in tissue capillaries was evaluated histologically by counting a minimum of 100 erythrocytes (RBC) in longitudinal sections of capillaries. Manual counts were performed in duplicate at 63X magnification, and the average percentage of infected erythrocytes (iRBC) in capillaries was determined for each tissue using the formula: (iRBC/total $\mathrm{RBC}) \times 100$. All tissue sections were examined by the same individual without knowledge of which strain the animal was inoculated with.

\section{Quantitative PCR on collected tissues}

Genomic DNA was extracted from frozen tissues (brain, lung, heart, kidney, liver, spleen, and skin) stored at $-80^{\circ} \mathrm{C}$. Tissues were thawed, homogenized and lysed using MP Biomedicals lysing matrix A as per manufacturer's recommendation (MP Biomedicals, Solon OH). Following the first centrifugation step, the supernatant was incubated at $56^{\circ} \mathrm{C}$ with proteinase $\mathrm{K}$ from the Qiagen Blood and Tissue DNA Extraction Kit (Qiagen, Valencia, CA), and extracted following the manufacturer's recommendation (Qiagen, Valencia, CA). Equivalent starting amounts of tissues $(0.1 \mathrm{~g})$ were processed in triplicate for each animal from each group. Quantitative PCR (qPCR) was performed using a previously published protocol targeting the merozoite surface antigen-1 gene (msa-1), with the exception of the $5^{\prime}$ primer (5'-GAT GCG TTT GCA CAT GCT AAG-3'). A positive control containing 10 ng of T2Bo gDNA, and negative control of naïve cow gDNA were included $[9,10]$.

\section{Statistical analysis}

Comparative analysis of sequestration at different biopsy time points, and tissue parasitemia, were analyzed using a 2-way ANOVA with repeated measures or 2-way ANOVA, respectively, with each followed by Bonferroni's multiple comparison tests. A one-tailed student's t-test was used for parasitemia comparison in blood (Graphpad Prism v. 5.0a).

\section{Results}

A cerebral cortical biopsy was obtained from all infected animals at the onset of clinical signs as determined by the first day of fever $\left(103^{\circ} \mathrm{F}\right)$ (Figure 1A). All biopsied 
animals received at least one dose of flunixin meglumine $(1.1 \mathrm{mg} / \mathrm{kg})$ to control localized inflammation and pain, which resulted in a slight decrease in body temperature in three of four animals. To avoid any confounding effect from this treatment, the second biopsies were obtained in both groups when severe clinical disease with fever was present (Figure 1A).

Cerebral sequestration of iRBC was observed in both T2Bo_vir and T2Bo_att infected animals throughout the experiment (Figure 1B). There was no significant difference in sequestration levels between T2Bo_vir and T2Bo_att infected animals at the onset of clinical signs (biopsy 1). However, the sequestration level in the T2Bo_vir infected animals increased significantly between the first and second biopsy (mean of $10.1 \%$ and $75.6 \%$ iRBC, respectively; $\mathrm{p}<0.0001$ ), as well as between the first biopsy and necropsy (mean of $10.1 \%$ and $82.8 \%$ iRBC, respectively; $\mathrm{p}<0.0001$ ) (Figure $1 \mathrm{C}$ ). In contrast, there was no significant elevation in sequestration level in T2Bo_att infected animals between the first and second biopsy or first biopsy

A

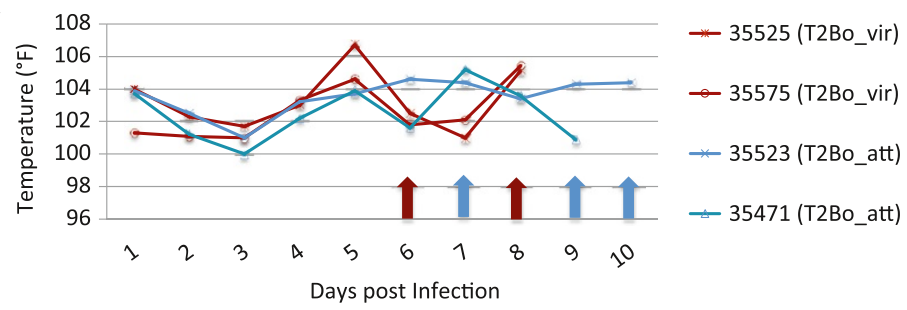

B Biopsy \#1

Biopsy \#2

Necropsy

1.

2.

3.

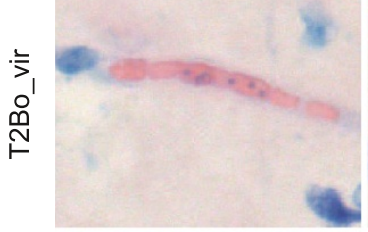

2.
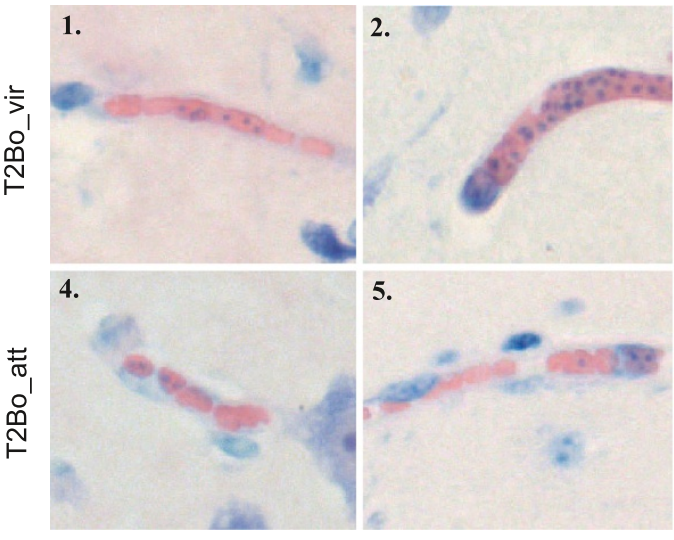

5.

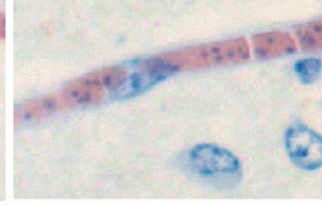

$10 \quad-10$

6.

$\mathbf{C}$

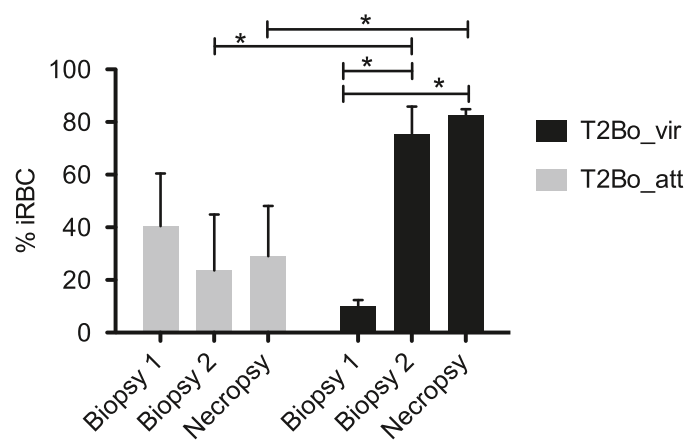

Figure 1 Sequential evaluation of cerebral capillary sequestration during acute babesiosis. (A) The timing of biopsy correlated with changes in rectal temperature during infection. Animals infected with T2Bo_vir are in red, and animals infected with T2Bo_att are in blue. The red arrows at days 6 and 8 indicate the first and second biopsy for T2Bo_vir infected animals. The blue arrows at days 7 and 9-10 indicate the first and second biopsy, respectively, for T2Bo_att infected animals. (B) Representative photomicrographs of brain biopsies of either the T2Bo_vir or T2Bo_att infected group. First biopsy (panels 1 and 4) was taken one day following the onset of fever. Second biopsy (panels 2 and 5) was taken 2-3 days following the first biopsy. Panels 3 and 6 represent samples taken within one hour of death. (C) Levels of sequestration observed in brain biopsies. There is a significant difference in sequestration between first and second biopsies $(p<0.0001)$, as well as first biopsy and necropsy $(p<0.0001$ ) for the T2Bo_vir group. A significant difference between the T2Bo_vir and T2Bo_att groups for second biopsy and necropsy $(p<0.05)$ was also observed. 
and necropsy (mean of 40.42\%, 23.6\%, and 29.0\% respectively). The capillary sequestration level between T2Bo_vir and T2Bo_att infected animals at the time of the second biopsy and necropsy were also significantly different (Figure 1C, mean of $75.6 \%$ vs $23.6 \%$ (second biopsy), and $82.8 \%$ vs $29.0 \%$ (necropsy), respectively; $\mathrm{p}<0.05$ ).

The only statistically significant differences in the level of parasite numbers between the T2Bo_vir and T2Bo_att groups were in the cerebrum and kidney, with significantly higher number of parasites found in the T2Bo_vir group (Table 1). This observation could be due to the tissue-tropism of the virulent strain and corroborates previous reports of sequestration of virulent strains of $B$. bovis in brain and renal capillaries [2].

While in vivo brain biopsies provide a unique analysis during acute disease, the challenges of performing these biopsies in large animals limits the total number of animals that can be examined in a study. Nonetheless, even with a small group size, our findings that the overall sequestration was lower in T2Bo_att infected animals than those infected with the parental virulent strain are statistically significant. Factors that may impact these results include variation in the initial or circulating parasite load, and differences in innate or adaptive immune response to parental and attenuated strains. Since the number of infected erythrocytes used in the inoculum for both groups was the same, the experiment was terminated prior to development of a protective immune response, and the time course of the experiment varied by only two days, the differential tissue sequestration levels observed are likely due to the nature of the inocula.

The presence of sustained sequestration with no signs of neurovirulence leads us to conclude that cytoadherence and sequestration, while associated with neurovirulence, may not be solely responsible. One explanation of the findings is that the attenuated strain may have reverted to neurovirulence once introduced back into a spleen-intact animal, a phenomenon reported experimentally in B. bovis [5,11] and in Plasmodium spp. [12-14]. However, in the field this is uncommon as attenuated strains of B. bovis

Table 1 Parasite numbers in tissue (copies/g) of T2Bo_vir and T2Bo_att infected animals

\begin{tabular}{lcc}
\hline Tissue & T2Bo_vir [SEM] & T2Bo_att [SEM] \\
\hline Cerebrum & $8.92 \mathrm{E}+05^{\mathbf{a}}[3.14 \mathrm{E}+05]$ & $2.06 \mathrm{E}+05[6.80 \mathrm{E}+04]$ \\
Lung & $6.91 \mathrm{E}+04[6.10 \mathrm{E}+03]$ & $2.07 \mathrm{E}+04[6.27 \mathrm{E}+03]$ \\
Heart & $2.70 \mathrm{E}+05[6.49 \mathrm{E}+04]$ & $5.21 \mathrm{E}+04[1.44 \mathrm{E}+04]$ \\
Liver & $4.41 \mathrm{E}+04[1.23 \mathrm{E}+04]$ & $1.30 \mathrm{E}+04[1.47 \mathrm{E}+03]$ \\
Kidney & $1.26 \mathrm{E}+06^{\mathbf{a}}[3.31 \mathrm{E}+05]$ & $1.09 \mathrm{E}+05[1.98 \mathrm{E}+04]$ \\
Spleen & $6.44 \mathrm{E}+05[3.16 \mathrm{E}+05]$ & $9.15 \mathrm{E}+04[4.11 \mathrm{E}+04]$ \\
Skin & $0.00 \mathrm{E}+00[0.00 \mathrm{E}+00]$ & $0.00 \mathrm{E}+00[0.00 \mathrm{E}+00]$
\end{tabular}

${ }^{a}$ Significant difference between the two groups in the cerebrum $(p<.05)$ and kidney $(p<.0001)$. have been used for extended periods as field vaccines without reversion to virulence [1]. The lack of neurovirulence in animals infected with T2Bo_att could be due to repertoire differences of parasite-derived proteins involved with cytoadhesion, such as the VESA1, which may then affect the binding of iRBC with endothelial cell receptors $[15,16]$. Comparative genome analysis of T2Bo_vir and T2Bo_att strains reveals genomic diversity reduction, including changes in the ves gene repertoire [8]. This finding supports the suggestion that genomic differences may contribute to phenotypic variability. Alternatively, a threshold level of iRBC cytoadherence within cerebral capillaries may be necessary for clinically expressed neurovirulence.

\section{Conclusion}

We hypothesized that the lack of neurovirulence in T2Bo_att infected animals is associated with an absence of cytoadherence and sequestration in cerebral capillaries. Our results demonstrate that attenuation with loss of neurovirulence does result in a significant reduction, but not total elimination of sequestration. Ongoing experiments will analyze transcriptomic expression profiles between the two members of this strain pair, and evaluate additional strain pairs in order to better understand the mechanisms of attenuation.

\section{Competing interests}

The authors declare that they have no competing interests.

\section{Authors' contribution}

KSS: performed the study, collected and analyzed blood and tissue samples, prepared the manuscript. TFM: assisted with study design, data analysis and interpretation, writing and manuscript revision. AJA: prepared animals before each brain biopsy, assisted during each surgery, monitored animals post surgery, and manuscript revision. ACA: performed the brain biopsy surgery, and manuscript revision. AOTL: assisted with study design, data analysis and interpretation, writing and manuscript revision. All authors read and approved the final manuscript.

\section{Acknowledgements}

We thank Dr. Ignacio Echaide for providing the blood stabilates of the virulent and attenuated derivative strain pair. We also thank Ralph Horn, James Allison, Emma Karel, and Sara Davis in the USDA Animal Research Unit for animal care and technical assistance, and the Histology Section of the Washington Animal Disease Diagnostic Laboratory for preparation of tissue slides. This project is supported by National Institutes of Health Mentored Research Scientist Development grant K01-OD01154-02 and USDA cooperative agreement \#58-5348-7-528.

\section{Author details}

'Department of Veterinary Microbiology and Pathology, College of Veterinary Medicine, Washington State University, Pullman, WA 99164-7040, USA. ${ }^{2}$ Paul G. Allen School for Global Animal Health, College of Veterinary Medicine, Washington State University, Pullman, WA 99164-7040, USA. ${ }^{3}$ Department of Veterinary Clinical Sciences, College of Veterinary Medicine, Washington State University, Pullman, WA 991674-7040, USA. 


\section{References}

1. Callow LL, Dalgliesh RJ, De Vos AJ: Development of effective living vaccines against bovine babesiosis-the longest field trial? Int J Parasitol 1997, 27(7):747-767.

2. Everitt JI, Shadduck JA, Steinkamp C, Clabaugh G: Experimental Babesia bovis infection in Holstein calves. Vet Pathol 1986, 23(5):556-562.

3. Nevils MA, Figueroa JV, Turk JR, Canto GJ, Le V, Ellersieck MR, Carson CA: Cloned lines of Babesia bovis differ in their ability to induce cerebral babesiosis in cattle. Parasitol Res 2000, 86(6):437-443.

4. MacPherson GG, Warrell MJ, White NJ, Looareesuwan S, Warrell DA: Human cerebral malaria: A quantitative ultrastructural analysis of parasitized erythrocyte sequestration. The Am J Path 1985, 119(3):385-401.

5. Callow LL, Mellors LT, McGregor W: Reduction in virulence of Babesia bovis due to rapid passage in splenectomized cattle. Int J Parasitol 1979, 9(4):333-338.

6. Avril M, Tripathi AK, Brazier AJ, Andisi C, Janes JH, Soma VL, Sullivan DJ Jr, Bull PC, Stins MF, Smith JD: A restricted subset of var genes mediates adherence of Plasmodium falciparum-infected erythrocytes to brain endothelial cells. Proc Natl Acad Sci USA 2012, 109(26):E1782-E1790.

7. Aikawa M, Pongponratn E, Tegoshi T, Nakamura K, Nagatake T, Cochrane A, Ozaki LS: A study on the pathogenesis of human cerebral malaria and cerebral babesiosis. Mem Inst Oswaldo Cruz 1992, 87(Suppl 3):297-301.

8. Lau AO, Kalyanaraman A, Echaide I, Palmer GH, Bock R, Pedroni MJ, Rameshkumar M, Ferreira MB, Fletcher TI, McElwain TF: Attenuation of virulence in an apicomplexan hemoparasite results in reduced genome diversity at the population level. BMC Genomics 2011, 12:410.

9. Howell JM, Ueti MW, Palmer GH, Scoles GA, Knowles DP: Persistently infected calves as reservoirs for acquisition and transovarial transmission of Babesia bovis by Rhipicephalus (Boophilus) microplus. J Clin Microbiol 2007, 45(10):3155-3159.

10. Bastos RG, Ueti MW, Guerrero FD, Knowles DP, Scoles GA: Silencing of a putative immunophilin gene in the cattle tick Rhipicephalus (Boophilus) microplus increases the infection rate of Babesia bovis in larval progeny. Parasit Vectors 2009, 2(1):57.

11. Timms P, Stewart NP, De Vos AJ: Study of virulence and vector transmission of Babesia bovis by use of cloned parasite lines. Infect Immun 1990, 58(7):2171-2176.

12. David PH, Hommel M, Miller LH, Udeinya IJ, Oligino LD: Parasite sequestration in Plasmodium falciparum malaria: spleen and antibody modulation of cytoadherence of infected erythrocytes. Proc Natl Acad Sci USA 1983, 80(16):5075-5079.

13. Barnwell JW, Howard RJ, Miller LH: Altered expression of Plasmodium knowlesi variant antigen on the erythrocyte membrane in splenectomized rhesus monkeys. J Immunol 1982, 128(1):224-226.

14. Barnwell JW, Howard RJ, Coon HG, Miller LH: Splenic requirement for antigenic variation and expression of the variant antigen on the erythrocyte membrane in cloned Plasmodium knowlesi malaria. Infect Immun 1983, 40(3):985-994.

15. O'Connor RM, Allred DR: Selection of Babesia bovis-infected erythrocytes for adhesion to endothelial cells coselects for altered variant erythrocyte surface antigen isoforms. J Immunol 2000, 164(4):2037-2045.

16. Allred DR, Al-Khedery B: Antigenic variation and cytoadhesion in Babesia bovis and Plasmodium falciparum: different logics achieve the same goal. Mol Biochem Parasitol 2004, 134(1):27-35.

\section{Submit your next manuscript to BioMed Central and take full advantage of:}

- Convenient online submission

- Thorough peer review

- No space constraints or color figure charges

- Immediate publication on acceptance

- Inclusion in PubMed, CAS, Scopus and Google Scholar

- Research which is freely available for redistribution

Submit your manuscript at www.biomedcentral.com/submit
C) BioMed Central 